\title{
Evaluation of the Protective Effects of Quercetin, Rutin, Resveratrol, Naringenin and Trolox Against Idarubicin-Induced DNA Damage
}

\author{
Haydar Çelik ${ }^{1,2}$ and Emel Arinç ${ }^{1}$ \\ ${ }^{1}$ Biochemistry Graduate Programme and Department of Biological Sciences, Middle East Technical University, 06531 \\ Ankara, Turkey \\ ${ }^{2}$ Present address: Food Engineering Department, Engineering Faculty, Erciyes University, 38039 Kayseri, Turkey
}

Received, May 24, 2010; Revised, July 13, 2010; Accepted, July 14, 2010; Published, July 14, 2010.

\begin{abstract}
PURPOSE. Idarubicin is a synthetic anthracycline anticancer drug widely used in the treatment of some hematological malignancies. The studies in our laboratory have clearly demonstrated that idarubicin can undergo reductive bioactivation by NADPH-cytochrome $\mathrm{P} 450$ reductase to free radicals with resulting formation of DNA strand breaks, which can potentially contribute to its genotoxic effects [Çelik, H., Arinç, E., Bioreduction of idarubicin and formation of ROS responsible for DNA cleavage by NADPHcytochrome P450 reductase and its potential role in the antitumor effect. J Pharm Pharm Sci, 11(4):68-82, 2008]. In the current study, our aim was to investigate the possible protective effects of several phenolic antioxidants, quercetin, rutin, resveratrol, naringenin and trolox, against the DNA-damaging effect of idarubicin originating from its P450 reductase-catalyzed bioactivation. METHODS. DNA damage was measured by detecting single-strand breaks in plasmid pBR322 DNA using a cell-free agarose gel method. RESULTS. Our results indicated that, among the compounds tested, quercetin was the most potent antioxidant in preventing DNA damage. Quercetin significantly decreased the extent of DNA strand breaks in a dose-dependent manner; $100 \mu \mathrm{M}$ of quercetin almost completely inhibited the DNA strand breakage. Unlike quercetin, its glycosidated conjugate rutin, failed to provide any significant protection against idarubicin-induced DNA strand breaks except at the highest concentration tested $(2 \mathrm{mM})$. The protective effects of other antioxidants were significantly less than that of quercetin even at high concentrations. Quercetin was found to be also an effective protector against DNA damage induced by mitomycin C. CONCLUSION. We conclude that quercetin, one of the most abundant flavonoids in the human diet, is highly effective in reducing the DNA damage caused by the antitumor agents, idarubicin and mitomycin C, following bioactivation by $\mathrm{P} 450$ reductase.
\end{abstract}

\section{INTRODUCTION}

In recent years, flavonoids and other phenolic compounds of plant origin have received increasing attention, especially in the field of pharmaceutical sciences and medicine, due to their potential to prevent a number of chronic and degenerative diseases including cancer and cardiovascular diseases (1-4). These compounds have been shown to exert a wide range of antioxidant properties in vitro, and most of their health-promoting effects have been attributed to their antioxidant action including their ability to scavenge reactive oxygen species (ROS), chelate metal ions and terminate free radical reactions (5). The flavonoids comprise the largest group of plant polyphenols found ubiquitously in significant quantities in vegetables and fruits as wells as in plant-derived food products and beverages such as tea and wine. The average daily intake of total flavonoids is estimated to be a few hundred of milligrams (expressed as aglycones), which indicates a substantial exposure of humans to these phytochemicals (6).

A variety of studies, both in vitro and in vivo, have shown that flavonoids possess several biological and pharmacological activities including anticancer, antioxidant, antimutagenic, antiviral, antimicrobial, anti-inflammatory and immuno-modulatory effects. Although the precise cellular and molecular mechanisms underlying such effects of flavonoids are largely unknown, several mechanisms have been proposed for their protective effects. These include the ability of flavonoids to act as antioxidants, direct radical scavengers, metal ion chelators, carcinogen inactivators, modulators of gene expression and DNA repair, hormones (including neurotransmitters), antihormones, inhibitors of

Corresponding Author: Assist. Prof. Dr. Haydar Çelik, Food Engineering Department, Engineering Faculty, Erciyes University, 38039 Kayseri, Turkey, E-mail: celik@erciyes.edu.tr 
enzyme and inducers of apoptosis $(1,7,8)$. However, in spite of a large number of studies pointing to the importance of flavonoids for the prevention of cardiovascular diseases, cancer and other chronic diseases, more recent studies challenge the in vivo efficacy of flavonoids. These studies indicate that flavonoids themselves are of little or no direct antioxidant value under in vivo conditions based on their limited bioavailability and extensive metabolism in humans (9).

Although it is still debatable, several animal and human studies have suggested that dietary supplementation of patients receiving chemotherapy with antioxidants might improve the efficacy of anticancer treatment by ameliorating the free-radical mediated toxicity and adverse effects in normal cells induced by antitumor agents (10-12). The mechanism of serious side-effects of chemotherapy drugs such as anthracycline-related cardiomyopathy and bleomycin-induced pulmonary toxicity appears to involve the formation of free radicals leading to oxidative stress (13). Free radicals may also be responsible for the genotoxic effects of such antineoplastic drugs to induce secondary malignancies. Since natural antioxidant compounds are important candidate agents for their potential use in chemoprevention and/or during or after cancer chemotherapy, extensive studies, both in vitro and in vivo, are currently being conducted on this subject.

Idarubicin is a second-generation anthracycline analog which is clinically effective against acute myelogenous leukemia and some other hematological malignancies (14). Conventional anthracyclines such as doxorubicin and daunorubicin have been extensively utilized since the 1960's in the clinic for the treatment of a variety of human tumors, but their clinical use has been limited by dose-dependent cardiotoxicity. Consequently, extensive efforts have been made to improve the toxicity profile of parent anthracyclines, which have resulted in the appearance of novel structural analogs.

Idarubicin (a daunorubicin derivative) is one such an analog which has demonstrated reduced cardiotoxicity over daunorubicin and doxorubicin (14). However, despite its unique features over other anthracyclines, idarubicin is not free from side effects. Anthracyclines produce their antitumor effects through several proposed mechanisms including inhibition of DNA topoisomerase II resulting in the induction of usually lethal DNA double-strand breaks, intercalation into DNA, thereby interfering with
DNA and RNA synthesis and production of free radicals (15).

The studies in our laboratory have clearly demonstrated that idarubicin can undergo reductive bioactivation by purified NADPHcytochrome $\mathrm{P} 450$ reductase with resulting formation of single-strand breaks in DNA. This damage was shown to be due to the formation of ROS during one-electron reduction of idarubicin by $\mathrm{P} 450$ reductase, which can potentially contribute to the genotoxicity of this antineoplastic drug (16-18).

In the present study, using a sensitive and well-defined in vitro pBR322 plasmid DNA damage assay which is free from the interferences caused by cellular defense and DNA repair, we investigated the possible protective effects of several phenolic antioxidants including quercetin, rutin, resveratrol, naringenin and trolox against the DNA-damaging effect of idarubicin originating from its NADPH-cytochrome P450 reductase-catalyzed bioactivation which have not been elucidated before.

\section{MATERIALS AND METHODS}

\section{Chemicals}

Idarubicin hydrochloride, quercetin, rutin, naringenin and trolox were purchased from Sigma-Aldrich Chemical Company, Saint Louis, Missouri, USA. Mitomycin C was obtained from Kyowa Hakko Kogyo Co., Ltd., Tokyo, Japan. Plasmid pBR322 DNA was purchased from Fermentas International Inc., Ontario, Canada. Resveratrol was kindly provided by Mikro-Gen Ltd., İstanbul, Turkey. Agarose and $\beta$ nicotinamide adenine dinucleotide phosphate, reduced form (NADPH) were purchased from Applichem, Darmstadt, Germany. All other chemicals used were obtained from commercial sources at the highest grade of purity available.

\section{Preparation of phenobarbital (PB)-treated rabbit liver microsomes and purification of NADPH-cytochrome $\mathbf{P 4 5 0}$ reductase}

Liver microsomes from PB-treated rabbits were prepared by differential centrifugation by using the combination of the methods described by Adali and Arinç (19) and Arinç and Sen (20). Homogenization was performed in $1.15 \% \mathrm{KCl}$ solution containing $2 \mathrm{mM}$ EDTA, $0.25 \mathrm{mM} \varepsilon$ ACA and $0.1 \mathrm{mM}$ PMSF. The washed microsomal pellets were finally re-suspended in 
$25 \%$ glycerol containing $1 \mathrm{mM}$ EDTA at a volume of $0.5 \mathrm{ml}$ for each gram of liver. Microsomes were put in plastic bottles, gassed with nitrogen gas and stored at $-86^{\circ} \mathrm{C}$ in a deep freezer until used for purification studies.

NADPH-cytochrome P450 reductase was purified to apparent homogeneity from PBinduced rabbit liver microsomes by slight modifications of the methods previously used in our laboratory for the purification of $\mathrm{P} 450$ reductase from a variety of tissues and species (21-25). Briefly, the purification procedure involved anion exchange chromatography of the detergent-solubilized microsomes on two successive DEAE-cellulose columns, affinity chromatography of the partially purified reductase on adenosine 2', 5'-diphosphate-Sepharose 4B column and further concentration and purification of the reductase on a final hydroxylapatite column. The purity of the final preparation of enzyme was evaluated by polyacrylamide gel electrophoresis under denaturing conditions (26). The final enzyme preparation was highly pure with respect to microsomes as judged by SDSPAGE and its absolute absorption spectrum (results not shown). The protein concentrations were determined by the method of Lowry et al. (27) with crystalline bovine serum albumin as a standard.

\section{DNA strand breakage assay}

The plasmid DNA experiments were performed as previously reported $(28,29)$ with some modifications (18). Briefly, the reaction mixtures contained supercoiled plasmid pBR322 DNA (1.0 $\mu \mathrm{g})$, idarubicin $(100 \mu \mathrm{M})$, purified rabbit liver P450 reductase $(0.2 \mu \mathrm{g})$, NADPH $(2.0 \mathrm{mM}), 100$ $\mathrm{mM}$ sodium phosphate buffer, $\mathrm{pH} 7.4$ and appropriate concentrations of antioxidants in a final volume of $60 \mu \mathrm{l}$ under aerobic conditions. The stock solutions of all the antioxidants tested were prepared freshly in methanol in eppendorf tubes, which were wrapped by aluminum foil in order to protect the chemicals from light. The final concentration of methanol in incubation mixtures was $2 \%$ of the reaction volume.

Untreated plasmid pBR322-alone control and solvent control incubations were also carried out in each run of gel electrophoresis. After incubating the samples at $37^{\circ} \mathrm{C}$ for 30 minutes under dimmed light, $5 \mu \mathrm{l}$ of agarose gel loading solution $(0.25 \%$ bromophenol blue, $0.5 \%$ SDS, $60 \%$ glycerol and $5 \mathrm{mM}$ EDTA) was mixed with
$20 \mu \mathrm{l}$ aliquots of incubation mixtures. The samples were then subjected to electrophoresis on a $1 \%$ agarose horizontal slab gel containing final concentration of $0.5 \mu \mathrm{g} / \mathrm{ml}$ of ethidium bromide in Tris-borate buffer $(45 \mathrm{mM}$ Tris-borate, $1 \mathrm{mM}$ EDTA).

After electrophoresis, resulting gels were photographed using a computer-based gel imaging instrument system (Infinity 3000-CN3000 darkroom) (Vilber Lourmat, Marne-laVallee Cedex 1, France) with Infinity-Capt Version 12.9 software, and DNA damage was quantified using Scion Image Version Beta 4.0.2 software. A correction factor of 1.22 was applied to the measured band intensities corresponding to the supercoiled form to compensate its reduced ethidium bromide uptake capacity (28).

DNA damage was expressed as \% OC (open circular)-DNA which was calculated by using the below formula (30): \% OC-DNA = (open circular DNA /total DNA) x 100. The extent of DNA damage in the presence of various concentrations of antioxidants was expressed as percentage of the solvent control $(100 \%)$ and calculated according to the method of Ashikaga et al. (30) which is given at the top of the next page.

\section{RESULTS}

The protective roles of quercetin, rutin, resveratrol, naringenin and trolox were evaluated using a pBR22 plasmid DNA damage assay in terms of their ability to limit DNA single-strand breaks generated during $\mathrm{P} 450$ reductase-catalyzed bioactivation of idarubicin. This assay relies on the conversion of supercoiled double-stranded DNA molecules (SC) into open circular form (OC), which displays retarded migration in agarose gel electrophoresis. The results of agarose gel electrophoresis are shown in Figures 1-3. When double-stranded plasmid pBR322 was incubated with idarubicin in the presence of purified rabbit liver $\mathrm{P} 450$ reductase and cofactor $\mathrm{NADPH}$, single-strand breaks were induced in DNA as shown by an increase in the relative intensity of the bands corresponding to the open circular form (Figures 1-3).

The protective effect of quercetin on idarubicin-induced single-strand breaks in plasmid pBR322 DNA was tested at six different concentrations ranging from 50 to $750 \mu \mathrm{M}$. In the presence of quercetin, the extent of idarubicininduced DNA damage decreased significantly in a concentration-dependent manner. 
DNA damage $(\%)=\frac{\% \text { OC-DNA (in the presence of antioxidant) }-\% \text { OC-DNA (untreated) }}{\% \text { OC-DNA (in the absence of antioxidant) }{ }^{\mathrm{b}}-\% \text { OC-DNA (untreated) }} \times 100$

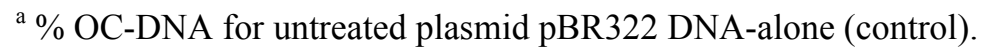

${ }^{\mathrm{b}}$ Since all the stock solutions of antioxidants were prepared in methanol, \% OC-DNA for the solvent control incubations was used to eliminate any protective effect coming from the solvent itself.
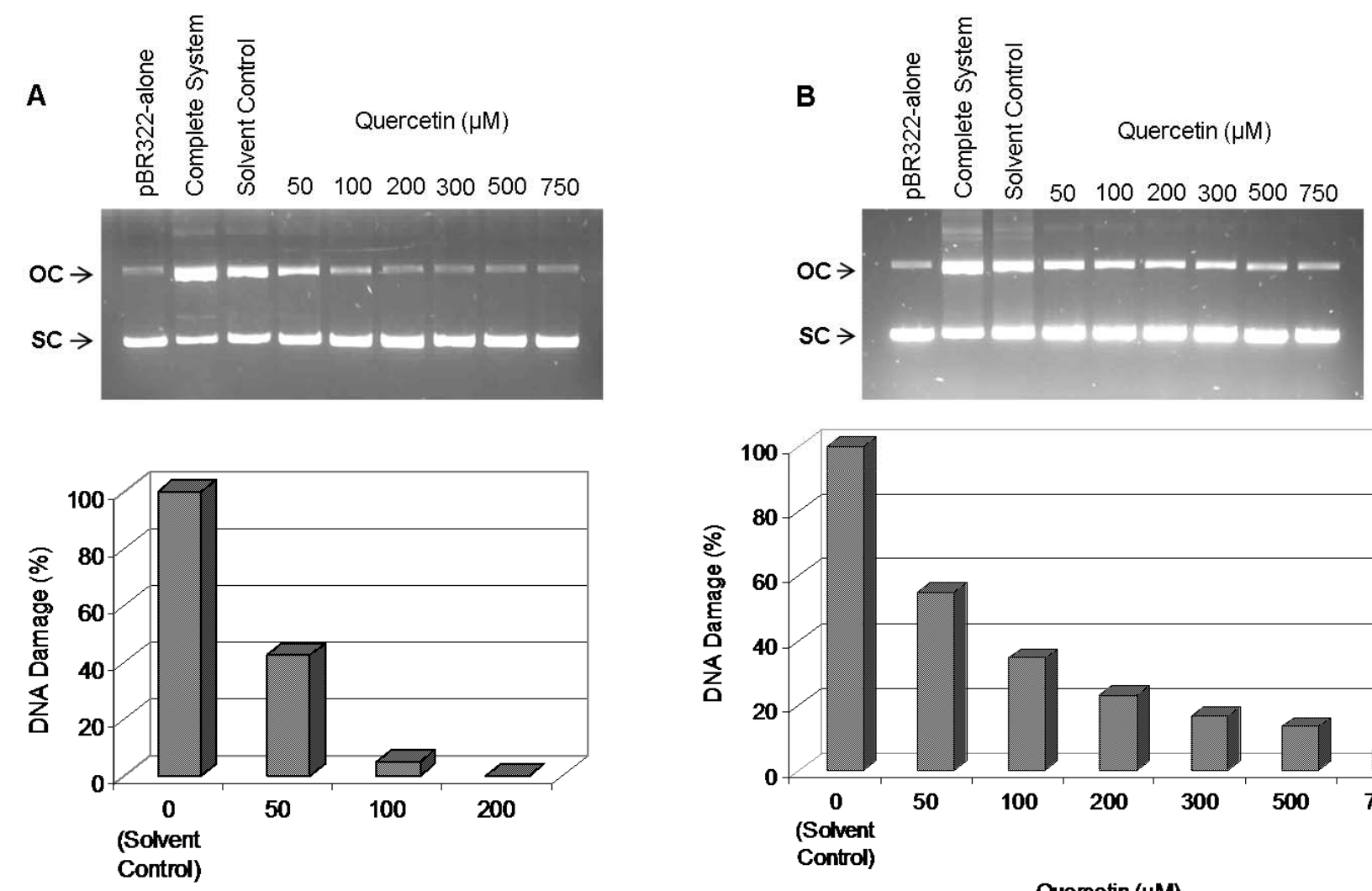

Quercetin $(\mu \mathrm{M})$

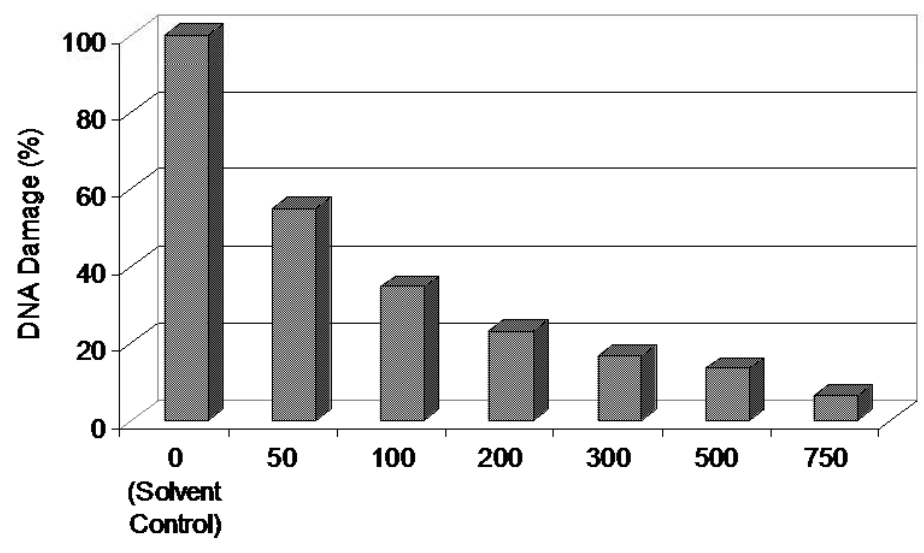

Quercetin $(\mu \mathrm{M})$

Figure 1. Effects of different concentrations of quercetin on pBR322 DNA single-strand breaks generated during NADPH-cytochrome $\mathrm{P} 450$ reductase (P450R)-catalyzed reductive activation of idarubicin (A) and mitomycin C (B) in the presence of cofactor NADPH. Supercoiled pBR322 DNA $(1.0 \mu \mathrm{g})$ was incubated for 30 minutes at $37^{\circ} \mathrm{C}$ in the presence of purified rabbit liver P450R $(0.2 \mu \mathrm{g})$ (for mitomycin $\mathrm{C}$, the amount of enzyme used was $2.0 \mu \mathrm{g}), \mathrm{NADPH}$ $(2.0 \mathrm{mM})$ and idarubicin or mitomycin $\mathrm{C}(100 \mu \mathrm{M})$ with various concentrations of quercetin in a final volume of $60 \mu \mathrm{l}$ reaction mixture. Following incubations, quantitative analysis and calculations of the extent of DNA damage were performed as described in "Materials and Methods". Complete system contained plasmid pBR322 DNA, P450R, idarubicin or mitomycin C and NADPH without quercetin. Solvent control contained plasmid pBR322 DNA, P450R, idarubicin or mitomycin C, NADPH and 2\% methanol. Results are given as percentage of the solvent control (assumed as $100 \%$ ). OC, open circular; SC, supercoiled.

The results in Figure 1A show that, even at a concentration of $50 \mu \mathrm{M}$, quercetin produced about a $58 \%$ protection against DNA damage and 100 $\mu \mathrm{M}$ of quercetin was enough for almost complete reduction of single-strand breaks (95\% protection) (Table 1).
In the current study, the protective role of quercetin against drug-induced generation of DNA strand breaks in the presence of P450 reductase and cofactor NADPH was also examined using mitomycin $\mathrm{C}$ in place of idarubicin in plasmid pBR322 system. 
Mitomycin $\mathrm{C}$ is a well characterized antitumor quinone that is known to be bioactivated by $\mathrm{P} 450$ reductase through oneelectron reduction and produces oxygen radicals under aerobic conditions (31). The flavonoid quercetin showed a dose-dependent protective effect against mitomycin $\mathrm{C}$-induced single-strand breaks in pBR322 DNA as similar to that observed against idarubicin-induced damage (Figure 1B). Treatment of plasmid DNA with 50 $\mu \mathrm{M}$ quercetin afforded about $45 \%$ reduction in DNA single-strand breaks. At $200 \mu \mathrm{M}$ of quercetin, it provided about a $77 \%$ protection and the presence of $750 \mu \mathrm{M}$ quercetin resulted in almost complete loss of DNA strand breaks (by more than $90 \%$ ) (Table 1).

Unlike quercetin, treatment of pBR322 DNA with its glycosidated conjugate rutin, at concentrations ranging from 100 to $750 \mu \mathrm{M}$, showed no protective effect against idarubicininduced DNA strand breaks (Figure 2). Incubation mixtures containing rutin at 100, 200, 500 and $750 \mu \mathrm{M}$ produced almost the same level of DNA strand breaks as the solvent control incubation. Duplicate studies were carried out for 100 and $500 \mu \mathrm{M}$ concentrations of rutin at which the extent of DNA damage produced was calculated to be $100.65 \pm 0.65 \%$ and $100.4 \pm 1.3 \%$, respectively, with respect to solvent control (assumed as 100\%). Rutin protected plasmid pBR322 DNA from idarubicin-induced damage at a higher concentration than quercetin. At $2 \mathrm{mM}$ concentration, it provided a $92.5 \%$ protection against DNA damage (Table 2).

Compared to quercetin and rutin, the protective effects of resveratrol and naringenin were less pronounced even at high concentrations. Neither resveratrol nor naringenin was active in reducing the amount of DNA single-strand breaks at the effective concentration range of quercetin (Figure 3A) (for naringenin, figure is not shown). Both antioxidants, at a concentration of $2 \mathrm{mM}$, protected DNA against idarubicin-induced formation of single-strand breaks only to the same extent of about $30 \%$ (Table 2). At the highest concentrations of the two compounds tested (5 $\mathrm{mM}$ ), resveratrol produced about a $62 \%$ reduction in idarubicin-induced formation of single-strand breaks, whereas naringenin displayed only a $41 \%$ inhibition (Table 2).

The protective effect of trolox against idarubicin-induced DNA single-strand breaks was assessed within the same concentration range (50$5000 \mu \mathrm{M})$ used for resveratrol and naringenin.

Incubation mixtures containing trolox at 50, $100,300,500,1000$ and $2000 \mu \mathrm{M}$ produced almost the same level of DNA strand breaks as the solvent control incubation. The percentage DNA damage values for these concentrations were calculated to be $96.3 \%, 95.9 \%, 99.8 \%$, $103.0 \%, 98.5 \%$ and $96.8 \%$, respectively, with respect to solvent control. The small fluctuations on the percentage protections observed might possibly be caused by handling errors while conducting the experiments. Trolox was found to be almost ineffective at all the above concentrations tested when compared to other antioxidants (Figure 3B). At $5 \mathrm{mM}$, trolox produced only a $13.2 \%$ protection against idarubicin-induced plasmid DNA strand breaks (Table 2).

\begin{tabular}{lcc}
\hline $\begin{array}{l}\text { Table 1. Protection of pBR322 plasmid DNA from idarubicin- and mitomycin C-induced DNA strand breaks } \\
\text { generated in the presence of NADPH-cytochrome P450 reductase and cofactor NADPH by quercetin }\end{array}$ \\
\hline \multicolumn{3}{c}{$\begin{array}{c}\text { Quercetin } \\
\text { Concentration ( } \mu \text { M) }\end{array}$} \\
\cline { 2 - 3 } & Protection (\%)* \\
\hline 50 & 57.5 & Mitomycin C-Induced \\
100 & 95.0 & 45.2 \\
200 & 100 & 65.4 \\
300 & 100 & 76.8 \\
500 & 100 & 83.3 \\
750 & 100 & 86.5 \\
& Idarubicin-Induced & 93.5 \\
\hline Experimental conditions are described in detail under "Materials and Methods". \\
* Calculations for protection (\%) values were performed using the formula given in "Materials and Methods". \\
\hline
\end{tabular}



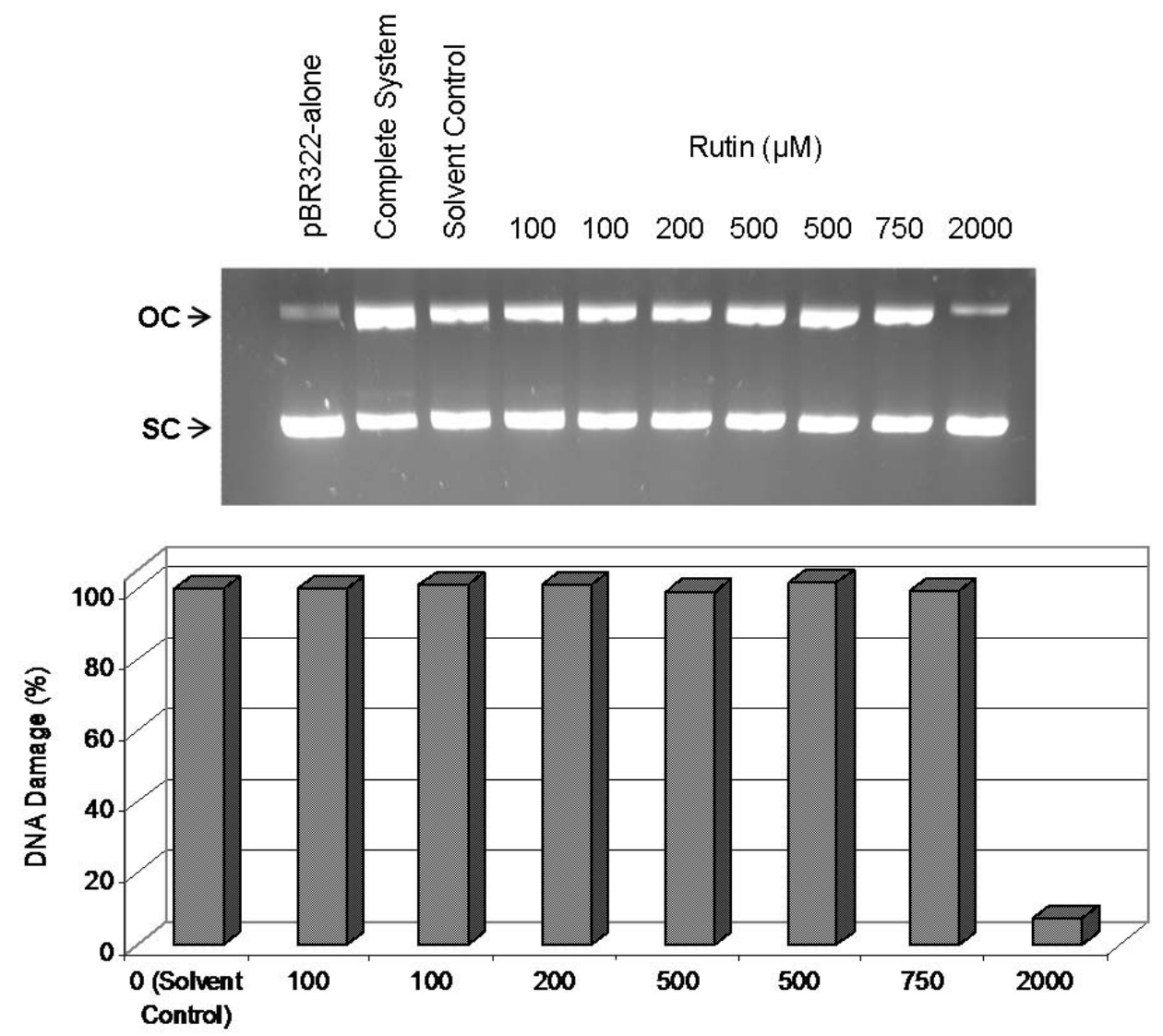

Rutin ( $\mu \mathrm{M})$

Figure 2. Effects of different concentrations of rutin on pBR322 DNA single-strand breaks generated during NADPHcytochrome P450 reductase-catalyzed reductive activation of idarubicin in the presence of cofactor NADPH. Supercoiled pBR322 DNA $(1.0 \mu \mathrm{g})$ was incubated for 30 minutes at $37^{\circ} \mathrm{C}$ in the presence of purified rabbit liver P450R $(0.2 \mu \mathrm{g})$, NADPH $(2.0 \mathrm{mM})$ and idarubicin $(100 \mu \mathrm{M})$ with various concentrations of rutin in a final volume of $60 \mu \mathrm{l}$ reaction mixture. Following incubations, quantitative analysis and calculations of the extent of DNA damage were performed as described in "Materials and Methods". Complete system contained plasmid pBR322 DNA, P450R, idarubicin and NADPH without antioxidants. Solvent control contained plasmid pBR322 DNA, P450R, idarubicin, $\mathrm{NADPH}$ and $2 \%$ methanol. Results are given as percentage of the solvent control (assumed as 100\%). OC, open circular; SC, supercoiled.

Table 2. Protection of pBR322 plasmid DNA from idarubicin-induced DNA strand breaks by rutin, resveratrol, naringenin and trolox at $2 \mathrm{mM}$ and $5 \mathrm{mM}$ concentrations

\begin{tabular}{|c|c|c|}
\hline \multirow{2}{*}{ Antioxidants } & \multicolumn{2}{|c|}{ Protection (\%)* } \\
\hline & $2 \mathrm{mM}$ & $5 \mathrm{mM}$ \\
\hline Rutin & 92.5 & N.D. \\
\hline Resveratrol & 26.7 & 62.3 \\
\hline Naringenin & 31.8 & 41.3 \\
\hline Trolox & 3.2 & 13.2 \\
\hline
\end{tabular}

N.D., not determined.

Experimental conditions are described in detail under "Materials and Methods".

* Calculations for protection (\%) values were performed using the formula given in "Materials and Methods". 

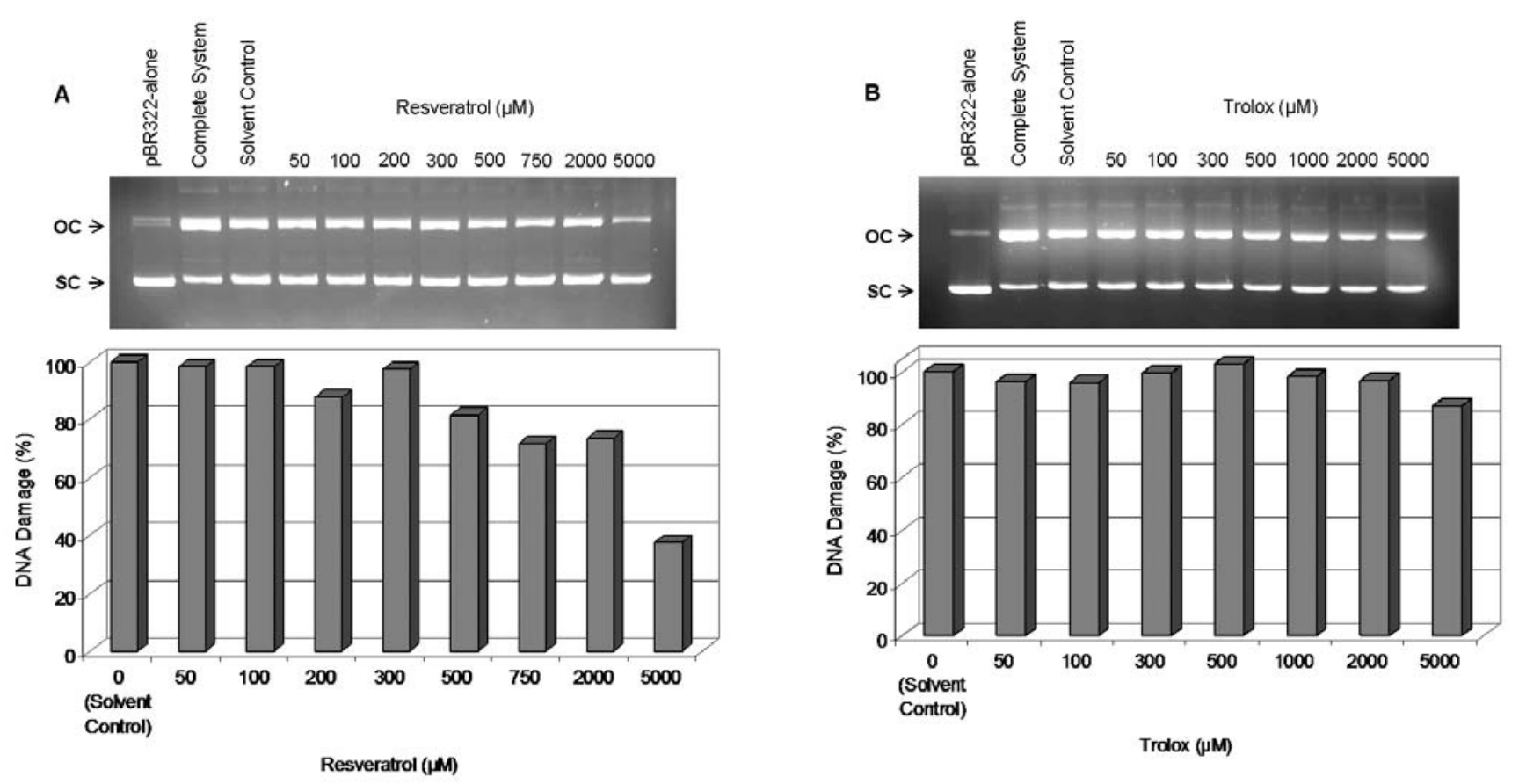

Figure 3. Effects of different concentrations of resveratrol (A) and trolox (B) on pBR322 DNA single-strand breaks generated during NADPH-cytochrome P450 reductase-catalyzed reductive activation of idarubicin in the presence of cofactor NADPH. Incubations were carried out under the same conditions as described in Figure 2 except that instead of rutin, either resveratrol or trolox at various concentrations was used as antioxidant in reaction mixtures. Following incubations, quantitative analysis and calculations of the extent of DNA damage were performed as described in "Materials and Methods". Complete system contained plasmid pBR322 DNA, P450R, idarubicin and NADPH without antioxidants. Solvent control contained plasmid pBR322 DNA, P450R, idarubicin, NADPH and 2\% methanol. Results are given as percentage of the solvent control (assumed as 100\%). OC, open circular; SC, supercoiled.

The ability of the tested compounds to protect DNA from free radical mediated damage was expressed in terms of $\mathrm{IC}_{50}$ values, which is the concentration that inhibits the formation of DNA damage by $50 \%$. The $\mathrm{IC}_{50}$ values of quercetin for inhibiting idarubicin- and mitomycin C-induced DNA strand breaks formation were almost the same and calculated as $43.5 \mu \mathrm{M}$ and $49.8 \mu \mathrm{M}$, respectively. The $\mathrm{IC}_{50}$ values of the other tested antioxidants for preventing idarubicin-induced DNA damage were in the millimolar range except trolox since even at very high concentrations it was not effective in protecting DNA (Figure 3B).

\section{DISCUSSION}

In the present study, exposure of plasmid pBR322 DNA to idarubicin in the presence of purified rabbit liver NADPH-cytochrome $\mathrm{P} 450$ reductase and cofactor NADPH resulted in the formation of DNA single-strand breaks. The previous studies in our laboratory have clearly demonstrated that oxygen radicals including superoxide anion, hydrogen peroxide and hydroxyl radical generated during reductive bioactivation of idarubicin by purified NADPH-cytochrome P450 reductase are involved in the DNA-damaging effect of this anticancer drug (18). There is an increasing amount of evidence that oxidative stress resulting from free radical generation is the main causative factor for the serious side effects of anthracyclines including dose-related cardiac toxicity (32). Idarubicin, a second-generation anthracycline analog, is a chemotherapy drug which is used in the treatment of certain hematological malignancies. Although idarubicin displays reduced cardiotoxicity and possesses unique features that distinguish it from other natural anthracyclines, it is not free from toxic side effects.

In this work, we investigated the ability of quercetin, rutin, resveratrol and naringenin and trolox to prevent free-radical mediated DNA damage evoked by idarubicin in the presence of P450 reductase and cofactor NADPH using a cellfree agarose gel method. The pBR322 plasmid DNA damage assay used in this study is a sensitive and well-defined in vitro assay system 
without the interferences caused by cellular antioxidant defense systems and DNA repair mechanisms. Our plasmid DNA experiments demonstrated that, among the tested antioxidants, quercetin was highly effective in protecting plasmid DNA against idarubicin-induced strand breakage.

Quercetin has been reported to be one of the most predominant flavonol-type flavonoids. The average daily intake of quercetin accounts for approximately $70 \%$ of the total flavonoid intake in Western diet with tea, onions and apples being the major contributors of flavonoids (33). Quercetin has been extensively studied as a pharmacological agent for its antioxidant properties and chemopreventive effects. Rutin (quercetin-3-rutinoside) is a glycoside of quercetin, and has been reported as one of the most commonly occurring flavonol glycosides in the human diet (33).

In our study, quercetin was found to have a higher ability to reduce the DNA-damaging effect of idarubicin than its conjugate flavonoid, rutin. Quercetin, at low concentrations (below $100 \mu \mathrm{M}$ ), was able to reduce significantly the amount of idarubicin-induced DNA strand breaks, whereas treatment of pBR3322 DNA with rutin, up to 750 $\mu \mathrm{M}$, did not produce any protective effect
(Figures 1 and 2, Table 1). Rutin reduced the level of DNA damage almost completely at a higher concentration of $2 \mathrm{mM}$ when compared to quercetin (Figure 2 and Table 2). In agreement with our results, Noroozi et al. (34) have demonstrated the greater antioxidant capacities of aglycone flavonoids over conjugated forms against hydrogen peroxide $\left(\mathrm{H}_{2} \mathrm{O}_{2}\right)$-induced DNA damage in human lymphocytes. Kim and Lee (35) also demonstrated, using vitamin $\mathrm{C}$ equivalent antioxidant capacity (VCEAC) assay, that glycosylated flavonoids were less effective antioxidants than their aglycone alone.

It has been shown that rutin, in humans, can be metabolized to quercetin by hydrolases present in the oral and intestinal microflora $(36,37)$. Thus, the antioxidant activity of rutin may increase through its enzymatic hydrolysis to the more bioactive aglycone form quercetin (Figure 4).

In the present study, we also assessed the protective effect of quercetin against pBR322 DNA single-strand breaks resulting from reductive bioactivation of mitomycin C. Since antioxidants except quercetin did not provide any effective protection against DNA strand scission induced by idarubicin, the protective effect of only quercetin was tested against mitomycin Cinduced DNA damage.

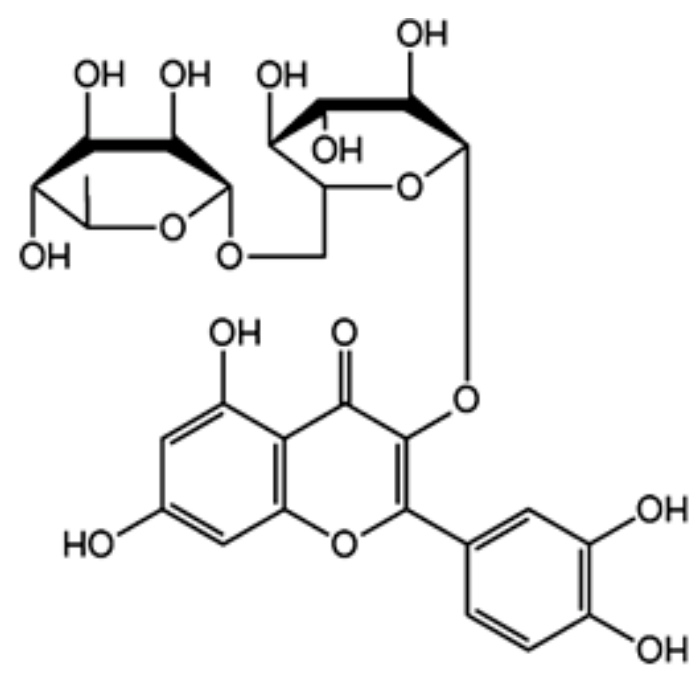

Rutin

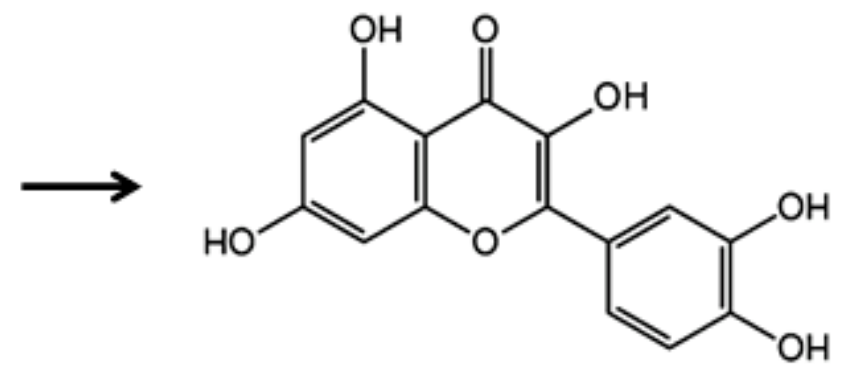

Quercetin

Figure 4. Enzymatic hydrolysis of rutin to the more bioactive aglycone form quercetin 
Similar to the findings with idarubicin, the plasmid DNA experiments with mitomycin $\mathrm{C}$ showed that quercetin effectively decreased the extent of DNA single-strand breaks induced by mitomycin $\mathrm{C}$ in a dose-dependent manner over a concentration range of 50-750 $\mu \mathrm{M}$ (Figure 1 and Table 1).

Resveratrol, a natural polyphenolic flavonoidlike antioxidant, is a phytoalexin found in the skin of redgrapes, nuts and berries and is a constituent of red wine. A number of in vitro studies have shown that resveratrol can act as an antioxidant, inhibits platelet aggregation and LDL oxidation and scavenges lipid hydroperoxyl free radicals as well as hydroxyl and superoxide radicals (38). Resveratrol has also been shown to possess chemopreventive and antitumor effects. Naringenin, one of the most abundant citrus bioflavonoids, has been reported to be pharmacologically active as an antioxidant, anticarcinogenic, antimutagenic, antiatherogenic, hepatoprotective and antifibrogenic agent. This substance has also been shown to be capable of inhibiting lipid peroxidation, scavenging free radicals and modulating cytochrome $\mathrm{P} 450$ dependent monooxygenase activities (39).
However, our experiments showed that, unlike quercetin, neither resveratrol nor naringenin exhibited a potent protective effect against idarubicin-induced DNA strand breaks (Figure 3 and Table 2).

Several in vitro studies have demonstrated that the chemical structures of individual flavonoids, more specifically the number and position of hydroxyl groups, affect their capacity to act as antioxidants. The presence of two hydroxyl groups in the ortho position or a hydroxyl group and an oxo group at proximal carbon positions have been shown as the main structural requirements for the greater capacity of flavonoids to protect DNA against oxidative damage $(34,40,41)$. Since quercetin possesses all these structural properties and contains higher number of hydroxyl groups compared to other antioxidants tested, our findings were in accordance with the general criteria given in these studies (Figures 4 and 5).

The results for trolox in the present study did not demonstrate any protective effect against idarubicin-induced single-strand breaks in plasmid DNA under the same experimental conditions (Figure 3B and Table 2).<smiles>O=C1CC(c2ccc(O)cc2)Oc2cc(O)cc(O)c21</smiles>

Naringenin<smiles>Oc1ccc(/C=C/c2cc(O)cc(O)c2)cc1</smiles>

Resveratrol<smiles>Cc1c(C)c2c(c(C)c1O)CCC(C)(C(=O)O)O2</smiles>

Trolox

Figure 5. Structures of antioxidants, naringenin, resveratrol and trolox 
Trolox is a water-soluble analogue of $\alpha$ tocopherol (Figure 5) with antioxidant and free radical scavenging properties, and has been demonstrated to protect DNA against oxidative damage in vitro $(42,43)$. On the other hand, Melidou et al. (41) and Anderson et al. (44) reported that trolox had no effect on $\mathrm{H}_{2} \mathrm{O}_{2-}$ or bleomycin-induced DNA damage in human lymphocytes.

In conclusion, the present investigation demonstrated that quercetin is an effective protector against idarubicin- and mitomycin $\mathrm{C}$ induced DNA strand breaks generated in the presence of purified NADPH-cytochrome P450 reductase and cofactor NADPH. Thus, the in vitro findings presented here suggest that quercetin containing diets may reduce anticancer druginduced toxicities and development of secondary malignancies following the completion of chemotherapy.

\section{ACKNOWLEDGEMENTS}

This work was supported by grants from The Scientific and Technological Research Council of Turkey (Project number: 106T139) and Middle East Technical University (Project number: BAP08-11-DPT-2002K120510).

\section{REFERENCES}

1. Havsteen, B.H., The biochemistry and medical significance of the flavonoids. Pharmacol Ther, 96:67-202, 2002.

2. Ross, J.A., Kasum, C.M., Dietary flavonoids: bioavailability, metabolic effects, and safety. Annu Rev Nutr, 22:19-34, 2002.

3. Surh, Y.J., Cancer chemoprevention with dietary phytochemicals. Nat Rev Cancer, 3:768-780, 2003.

4. Boudet, A.M., Evolution and current status of research in phenolic compounds. Phytochemistry, 68:2722-2735, 2007.

5. Fang, Y.Z., Yang, S., Wu, G., Free radicals, antioxidants, and nutrition. Nutrition, 18:872879, 2002.

6. Hollman, P.C., Katan, M.B., Dietary flavonoids: intake, health effects and bioavailability. Food Chem Toxicol, 37:937942, 1999.

7. Rice-Evans, C.A., Miller, N.J., Antioxidant activities of flavonoids as bioactive components of food. Biochem Soc Trans, 24:790-795, 1996.

8. Nijveldt, R.J., van Nood, E., van Hoorn, D.E., Boelens, P.G., van Norren, K., van Leeuwen, P.A., Flavonoids: a review of probable mechanisms of action and potential applications. Am J Clin Nutr, 74:418-425, 2001.

9. Lotito, S.B., Frei, B., Consumption of flavonoid-rich foods and increased plasma antioxidant capacity in humans: Cause, consequence, or epiphenomenon? Free Radic Biol Med, 41:1727-1746, 2006.

10. Lamson, D.W., Brignall, M.S., Antioxidants in cancer therapy; their actions and interactions with oncologic therapies. Altern Med Rev, 4:304-329, 1999.

11. Block, K.I., Antioxidants and cancer therapy: furthering the debate. Integr Cancer Ther, 3:342-348, 2004.

12. Prasad, K.N., Multiple dietary antioxidants enhance the efficacy of standard and experimental cancer therapies and decrease their toxicity. Integr Cancer Ther, 3:310-322, 2004.

13. Weijl, N.I., Cleton, F.J., Osanto, S., Free radicals and antioxidants in chemotherapyinduced toxicity. Cancer Treat Rev, 23:209240, 1997.

14. Borchmann, P., Hübel, K., Schnell, R., Engert, A., Idarubicin: a brief overview on pharmacology and clinical use. Int $\mathrm{J}$ Clin Pharmacol Ther, 35:80-83, 1997.

15. Gewirtz, D.A., A critical evaluation of the mechanisms of action proposed for the antitumor effects of the anthracycline antibiotics adriamycin and daunorubicin. Biochem Pharmacol, 57:727-741, 1999.

16. Çelik, H., Arinç, E., Comparison of the in vitro DNA-damaging potential of the two anticancer drugs idarubicin and mitomycin $\mathrm{C}$ in the presence of NADPH-cytochrome P450 reductase. Drug Metab Rev, 38 (Suppl. 1):185-186, 2006.

17. Çelik, H., Arinç, E., Mechanisms and involvements of NADPH-cytochrome P450 reductase and NADH-cytochrome b5 reductase in mitomycin $\mathrm{C}$ and idarubicin promoted DNA damage and "ROS" formation: a study with rabbit liver microsomes and purified enzymes. Drug Metab Rev, 38 (Suppl. 2):91-92, 2006.

18. Çelik, H., Arinç, E., Bioreduction of idarubicin and formation of ROS responsible for DNA cleavage by NADPH-cytochrome $\mathrm{P} 450$ reductase and its potential role in the antitumor effect. J Pharm Pharm Sci, 11:6882, 2008.

19. Adali, O., Arinç, E., Electrophoretic, spectral, catalytic and immunochemical properties of highly purified cytochrome P-450 from sheep lung. Int J Biochem, 22:1433-1444, 1990.

20. Arinç, E., Sen, A., Characterization of cytochrome P450-dependent mixed-function oxidase system of gilthead seabream (Sparus aurata; sparidae) liver. Comp Biochem 
Physiol B Biochem Mol Biol, 104:133-139, 1993.

21. Işcan, M.Y., Arinç, E., Kinetic and structural properties of biocatalytically active sheep lung microsomal NADPH-cytochrome $c$ reductase. Int J Biochem, 18:731-741, 1986.

22. Işcan, M.Y., Arinç, E., Comparison of highly purified sheep liver and lung NADPHcytochrome $\mathrm{P}-450$ reductases by the analysis of kinetic and catalytic properties. Int $\mathrm{J}$ Biochem, 20:1189-1196, 1988.

23. Sen, A., Arinç, E., Purification and characterization of cytochrome P450 reductase from liver microsomes of feral leaping mullet (Liza saliens). J Biochem Mol Toxicol, 12:103-113, 1998.

24. Arinç, E., Çelik, H., Biochemical characteristics of purified beef liver NADPHcytochrome P450 reductase. J Biochem Mol Toxicol, 16:286-297, 2002.

25. Bozcaarmutlu, A., Arinç, E., Effect of mercury, cadmium, nickel, chromium and zinc on kinetic properties of NADPHcytochrome $\mathrm{P} 450$ reductase purified from leaping mullet (Liza saliens). Toxicol In Vitro, 21:408-416, 2007.

26. Laemmli, U.K., Cleavage of structural proteins during the assembly of the head of bacteriophage T4. Nature, 227:680-685, 1970.

27. Lowry, O.H., Rosebrough, N.J., Farr, A.L., Randall, R.J., Protein measurement with the Folin phenol reagent. J Biol Chem, 193:265275, 1951.

28. Fisher, G.R., Gutierrez, P.L., Free radical formation and DNA strand breakage during metabolism of diaziquone by $\mathrm{NAD}(\mathrm{P}) \mathrm{H}$ quinone-acceptor oxidoreductase (DTdiaphorase) and NADPH cytochrome $c$ reductase. Free Radic Biol Med, 11:597-607, 1991.

29. Shen, T., Hollenberg, P.F., The mechanism of stimulation of NADPH oxidation during the mechanism-based inactivation of cytochrome P450 2B1 by N-methylcarbazole: redox cycling and DNA scission. Chem Res Toxicol, 7:231-238, 1994.

30. Ashikaga, T., Wada, M., Kobayashi, H., Mori, M., Katsumura, Y., Fukui, H., Kato, S., Yamaguchi, M., Takamatsu, T., Effect of the photocatalytic activity of $\mathrm{TiO}_{2}$ on plasmid DNA. Mutat Res, 466:1-7, 2000.

31. Seow, H.A., Penketh, P.G., Baumann, R.P., Sartorelli, A.C., Bioactivation and resistance to mitomycin C. Methods Enzymol, 382:221233, 2004.

32. Minotti, G., Menna, P., Salvatorelli, E., Cairo, G., Gianni, L., Anthracyclines: molecular advances and pharmacologic developments in antitumor activity and cardiotoxicity. Pharmacol Rev, 56:185-229, 2004.
33. Hertog, M.G., Hollman, P.C., Katan, M.B., Kromhout, D., Intake of potentially anticarcinogenic flavonoids and their determinants in adults in The Netherlands. Nutr Cancer, 20:21-29, 1993.

34. Noroozi, M., Angerson, W.J., Lean, M.E., Effects of flavonoids and vitamin $\mathrm{C}$ on oxidative DNA damage to human lymphocytes. Am J Clin Nutr, 67:1210-1218, 1998.

35. Kim, D.O., Lee, C.Y., Comprehensive study on vitamin $\mathrm{C}$ equivalent antioxidant capacity (VCEAC) of various polyphenolics in scavenging a free radical and its structural relationship. Crit Rev Food Sci Nutr, 44:253273, 2004.

36. MacDonald, I.A., Mader, J.A., Bussard, R.G., The role of rutin and quercitrin in stimulating flavonol glycosidase activity by cultured cellfree microbial preparations of human feces and saliva. Mutat Res, 122:95-102, 1983.

37. Bokkenheuser, V.D., Shackleton, C.H., Winter, J., Hydrolysis of dietary flavonoid glycosides by strains of intestinal Bacteroides from humans. Biochem J, 248:953-956, 1987.

38. Sun, A.Y., Simonyi, A., Sun, G.Y., The "French Paradox" and beyond: neuroprotective effects of polyphenols. Free Radic Biol Med, 32:314-318, 2002.

39. Pari, L., Gnanasoundari, M., Influence of naringenin on oxytetracycline mediated oxidative damage in rat liver. Basic Clin Pharmacol Toxicol, 98:456-461, 2006.

40. Rice-Evans, C., Flavonoid antioxidants. Curr Med Chem, 8:797-807, 2001.

41. Melidou, M., Riganakos, K., Galaris, D., Protection against nuclear DNA damage offered by flavonoids in cells exposed to hydrogen peroxide: the role of iron chelation. Free Radic Biol Med, 39:1591-1600, 2005.

42. Wu, T.W., Hashimoto, N., Wu, J., Carey, D., Li, R.K., Mickle, D.A., Weisel, R.D., The cytoprotective effect of Trolox demonstrated with three types of human cells. Biochem Cell Biol, 68:1189-1194, 1990.

43. Kumar, S.S., Chaubey, R.C., Devasagayam, T.P., Priyadarsini, K.I., Chauhan, P.S., Inhibition of radiation-induced DNA damage in plasmid pBR322 by chlorophyllin and possible mechanism(s) of action. Mutat Res, 425:71-79, 1999.

44. Anderson, D., Yu, T.W., Phillips, B.J., Schmezer, P., The effect of various antioxidants and other modifying agents on oxygen-radical-generated DNA damage in human lymphocytes in the COMET assay. Mutat Res, 307:261-271, 1994. 